\title{
A Model of Tournament Incentives with Corruption*
}

\author{
Bin Wang ${ }^{\dagger}$ \\ Jinan University
}

\author{
Yu Zheng ${ }^{\ddagger}$ \\ Queen Mary University of London \\ and CEPR
}

June 12, 2018

\begin{abstract}
The institution that has enabled decades of rapid economic growth in China features lower-level government officials competing for promotion to a higher level by promoting local economic growth. Theoretically, this tournament-style promotion scheme calls for a convex wage scale to effectively elicit effort. However, the empirically observed public-sector pay scale is rather concave in China. We reconcile the theoretical prediction on the wage progressivity with its empirical counterpart by recognizing other implicit forms of incentives of rising to the top made possible by another institutional feature of China: the top-down disciplinary inspection.
\end{abstract}

Keywords: Institution; Tournament; Corruption; China.

JEL codes: D73; J45; O43; P26.

*We are grateful to Kim-Sau Chung, Maitreesh Ghatak, David K. Levine, Yang Lu, Stephen L. Parente, and Jie Zheng for their useful comments. We thank the participants in the CEPREMAP India-China Conference 2019 at Warwick, the First World Congress of Comparative Economics in Rome and Singapore Economic Review Conference 2017, as well as seminar participants at the European University Institute, Tsinghua University, Hong Kong Baptist University, Jinan University and Shanghai University of Finance and Economics. The usual caveat applies. The work described in this article was fully supported by a grant from the Research Grants Council of the Hong Kong Administrative Region, China (Project No. CityU 198113).

${ }^{\dagger}$ Department of Economics, College of Economics, Jinan University; Address: No. 601, Huangpu Street West, Guangzhou, China. Email: binwang@jnu.edu.cn.

${ }^{\ddagger}$ Corresponding author: School of Economics and Finance, Queen Mary University of London, Mile End Road E1 4NS, London, UK. Email: yu.zheng@qmul.ac.uk. 


\section{Introduction}

The Chinese political institution that accompanied three decades of rapid economic growth is widely considered as having two essential characteristics: on one hand, there is regional decentralized economic management, and on the other, there is centralized cadre management (Xu, 2011). The local government officials who have a high level of autonomy in terms of economic decision making engage in a competition that rewards better local economic performance with promotion within the bureaucratic nomenclature. The effectiveness of this promotion exercise to promote local economic growth has been studied both theoretically (Maskin et al., 2000) and empirically (Li and Zhou, 2005; Jia et al., 2015).

Conceptually, the promotion exercise is sometimes referred to as resembling a rank-order tournament labor contract, ${ }^{1}$ which can induce an efficient level of effort from workers under a properly designed pay structure (Lazear and Rosen, 1981). The pay structure in such a tournament is shown to be convex in the sense that the pay increase between rungs of career ladders becomes larger as one moves up the rank (Rosen, 1986). While such compensation schemes are found in sports and corporations (Ehrenberg and Bognanno, 1990; Eriksson, 1999), the public-sector pay scale of the Chinese officials almost certainly falls short of it. The "3581" Project implemented in Beijing in 2004 portrays a pay scale that starts from an annual salary of 30,000 yuan for township/sub-division level officials, 50,000 yuan for county/section level officials, 80,000 yuan for prefecture/bureau level officials and 100,000 yuan for province/ministry level officials. Leaving the absolute level of the salaries aside, the increase in the salary across the bureaucratic spectrum appears hardly high-powered enough to be compatible with a rank-order tournament.

One way out is to recognize that the observed salary is only a "capitulation wage" to be supplemented by, for instance, corruption income (Becker and Stigler, 1974; Besley and McLaren, 1993). Several international rankings of corruption indices confirm the impression that corruption is wide-spread in China (see a review in Svensson (2005)). However, letting the corruption income accrue disproportionately to the top officials is not compatible with the essential features of the Chinese institution. The centralized personnel management means that corruption is monitored and penalized in a top down fashion. ${ }^{2}$ This implies

\footnotetext{
${ }^{1} \mathrm{Xu}$ (2011) gives the tournament interpretation to a seminal model of the organizational form of the Chinese government (Maskin et al., 2000). More recently, Li et al. (2018) adopt a Tullock contest model embedded in a multi-layer tournament to study target-setting in the Chinese government.

${ }^{2}$ China does not lack anti-corruption laws. The Anti-Unfair Competition Law of the PRC deals mainly with commercial bribery, while the Criminal Law of the PRC prohibits giving and receiving money or property to obtain any undue benefit. Penalties for the offense ranges from fines and confiscation to imprisonment and the death penalty. The law enforcement is however more subtle. Due to the inseparability of the judicial
} 
zero monitoring at the top. To minimize the potential massive abuse of power at the top, decentralizing economic management to lower-level governments effectively distances the top from a direct control over economic resources and limits the scope for corruption at the top.

So what is the grand prix to the winner of the tournament? We provide an explanation of how the rank-order tournament incentive can work in a Chinese institutional background. In its most parsimonious form, there are three logical steps in the argument. First, corruption, interpreted as misuse of power in the allocation of economic resources for personal gains, occurs where economic decisions are made. Due to decentralized economic management, it can occur anywhere except the top. Second, corruption income cannot be fully consumed contemporaneously, and hence contributes to wealth accumulation that forms the basis of an official's vested interest in winning the tournament. Third, the fact that the corruption inspection is implemented top-down means that the accumulated wealth is not safe until one rises to the top, and risen to the top, one can potentially benefit from being the inspector. Then, the grand prize at the top is not an opportunity to extract more rents, but the security with which to keep the wealth accumulated over one's career. This view logically weaves growth, corruption, tournament, and key features of the Chinese institution into a coherent story.

We formalize the idea by embedding a rank-order tournament model in a model of career concerns similar to Qian and Xu (1993) and Maskin et al. (2000). We interpret the lower-level government officials as managers to whom production tasks are delegated and the top official as disciplinary inspector to whom a corruption monitoring task is delegated. The officials are organized in a bureaucracy and incentivized by a rank-order tournament labor contract. We model the informational frictions explicitly. First, the lower-level government officials who undertake production needs to exert costly effort, which is only privately observable. Second, these officials who undertake production faces an opportunity to grow private wealth at an above market rate, which captures the potential for rent-seeking or corruption. The decision to exploit such an opportunity is also private, and hence to reveal such wrong-doing would require a monitoring technology, which is delegated to the top government official, to be consistent with the centralized personnel management. Last but not the least, upon

system and the Party, in practice, it is the Commission for Discipline Inspection of the Communist Party that monitors corruption related to government officials. The top leaders of the country are the members of the Standing Committee of the Politburo. Meanwhile, the highest organ in charge of the anti-corruption regulation is the Central Commission for Discipline Inspection, whose head has an administrative rank no higher than any member from the Standing Committee of Politburo. Disciplinary actions against members of the Standing Committee of the Politburo were unheard of until the recent case of Zhou Yongkang. In general, corruption charges against such high-profile officials are very rare and moreover not institutionalized. A recent paper by Che et al. (2017) studies the implications from granting criminal immunity to top leaders in China. 
disciplinary inspection, the outcome of the investigation is observed only to the inspector or the top official. This creates potential for collusion between the inspector and the official under investigation, which presents another inefficiency (Tirole, 1992). We believe these are very realistic problems the Chinese society at large faces in dealing with bureaucrats in an institution that fundamentally lacks checks and balances.

Within this framework, we solve for the optimal choice for the level of disciplinary inspection as well as the incentive structure or the wage prizes offered at each stage of the tournament to maximize total output net cost of incentives. We show that the only level of disciplinary inspection that can be realistically implemented is a lax one, under which all officials are indifferent between being corrupt or not. This is a consequence of the deeprooted informational frictions we model. With the epidemic of corruption inherent in the system, the optimal wage scale appears weak-powered. The savings in wages at the top are made possible by relying on bureacrauts' private wealth building as implicit reward. At an early stage of development, incorporating bureaucrat's personal wealth building as an implicit reward may not only be cost-saving, but also necessary when the state's tax collection capability is low or the government's budget is limited .

This paper makes two contributions. It is most closely related to the literature on the Chinese political institution, and in particular that on the Regionally Decentralized Authoritarian (RDA) regime (Du and Xu, 2007; Landry, 2008; Xu, 2011). We contribute to that literature by clarifying how a seemingly lower-powered public-sector pay scale is able to incentivize the government officials to work hard at promoting economic growth under the RDA regime. More generally, our results suggest that, during the course of development in China, good governance that produced tremendous economic growth may paradoxically require some level of corruption. This is especially true when the government budget is tight, so there is a limit to which one can use explicit wages to incentivize government officials. Formalizing this particular role of corruption in China's development is our second contribution, which complements the literature on the role of corruption during economic development (Tirole, 1994; Banerjee, 1997; Laffont and N'Guessan, 1999). As the country grows richer and the government function evolves, the public-sector pay needs to adjust accordingly to elicit the efficient level of effort at all levels of the government.

\section{The Model}

We follow the literature that studies how organization affects economic performance in the context of the Chinese bureaucracy (Qian and Xu, 1993; Maskin et al., 2000). The bureau- 
crats or officials are organized as managers in a hierarchy, to whom production tasks are delegated. Production takes costly effort, and therefore our primary concern is to find the set of incentives, in terms of a wage scheme along the hierarchy as well as the degree of disciplinary inspection which governs the scope for grey income, which maximizes the total output net cost of incentives. We assume all officials are risk neutral, rational and selfish, which implies that we must respect their individual incentive compatibility constraints.

The Geographic Structure of Technology. Production is organized in geographical terms. For simplicity, we consider two levels of geographical division: provinces and prefectures. There are two types of production tasks. The province-level task is to draw provincial development plans and invest in public infrastructure within the province. The prefecturelevel task is to draw prefectural development plans and improve local public infrastructure. The province-level task takes into account externalities across prefectures and economies of scale at the level of the province, and therefore has values independent of the tasks in prefectures under the province's jurisdiction. More formally, let the subscript $j$ indicate a province. Let the subscript $i j$ indicate a prefecture $i$ in the province $j$. The final output, interpreted as local output growth rate, in each prefecture is denoted $y_{i j}$, which is jointly determined by the output of the provincial-level task, $q_{j}$, and the output of the prefectural-level task, $q_{i j}$. The parameter $\mathcal{A}$ is a productivity parameter to be calibrated later.

$$
y_{i j}=\mathcal{A} q_{j}^{\alpha} q_{i j}^{\beta}, \text { where } \alpha+\beta<1
$$

Some justifications are warranted here. The idea that both province-level and prefecturelevel tasks contribute to the production of the final output is not new. Li et al. (2018) is a recent example that emphasizes this interdependence. However, our set-up differs from theirs along two dimensions. First, our production function of the final output features decreasing return to scale. This is to ensure, later on, that when we solve for the optimal set of incentives, we have a well-behaved concave objective function optimized over a convex set. Note that we have abstracted away from having an input from the center-level, which captures the fact that economic decisions are typically decentralized to local governments in China. Second, while in Li et al. (2018), the output at a given task is a one-to-one function of the effort of the agent undertaking that task, we model the moral hazard problem of the officials explicitly. To do that, we assume that the output of the province-level (prefecturelevel) task is an outcome of both an effort input from the official who is in charge of that 
task and a luck component:

$$
\ln q_{j}=\ln x_{j}+\ln \eta_{j}
$$

where $x_{j}$ is the effort input and $\eta_{j}$ is the luck component that is lognormally distributed: $\ln \eta_{j} \sim N\left(-\frac{1}{2} \alpha \sigma_{1}^{2}, \sigma_{1}^{2}\right)$. Denote the distribution of the shock by $G\left(\eta_{j}\right)$. Likewise, the output of the prefectural-level task, $q_{i j}$ is:

$$
\ln q_{i j}=\ln x_{i j}+\ln \varepsilon_{i j}
$$

where $x_{i j}$ is the effort input and $\varepsilon_{i j}$ is the luck component: $\ln \varepsilon_{i j} \sim N\left(-\frac{1}{2} \beta \sigma_{2}^{2}, \sigma_{2}^{2}\right)$. Denote the distribution of the shock by $F\left(\varepsilon_{i j}\right)$. The variances of the shocks are set up so that the expected final output in prefecture $i$ of province $j$ is

$$
E\left(y_{i j}\right)=\mathcal{A} E\left(q_{j}^{\alpha}\right) E\left(q_{i j}^{\beta}\right)=\mathcal{A} x_{j}^{\alpha} x_{i j}^{\beta}
$$

Suppose that there are $n_{1}$ province-level tasks and, in each province, there are $n_{2}$ prefecturelevel tasks. The expected aggregate final output in this economy is then

$$
E(Y)=\sum_{j=1}^{n_{1}} \sum_{i=1}^{n_{2}} E\left(y_{i j}\right)=\sum_{j=1}^{n_{1}} \sum_{i=1}^{n_{2}} \mathcal{A} x_{j}^{\alpha} x_{i j}^{\beta} .
$$

Panel (a) of Figure 1 illustrates an example of such a production structure with $n_{1}=3$ and $n_{2}=2$. The dashed squares illustrate provinces, each of which is composed of two prefectures. The production in each prefecture uses the outputs from two prefecture-level tasks (the blue dots) and the output from the province-level task (the red dot). This is a snapshot of the production structure at each point in time.

The Informational Structure. During production, the effort input is private information to whoever undertakes the production. Therefore, it is impossible to directly base the wage incentive on effort, instead it is based on realized output, as in a typical moral hazard problem.

In addition, an official who is in charge of the province-level (prefecture-level) task has an opportunity to grow his personal wealth at some above market rate of return, $r_{1}\left(r_{2}\right)$. We interpret the act of growing private wealth at an above market return as a form of corruption. It captures cases such as taking advantage of one's office to seek benefits for his relatives' 
business. ${ }^{3}$ In the baseline model, growing private wealth does not affect the official's ability to undertake his production task, but we relax this assumption and let corruption to come at a cost of production in Section 3.3.

Since the act of corruption is also private information, a corruption monitoring technology is used by a disciplinary inspector. The inspector investigates the officials in charge of the production probabilistically. Once inspected, whether the official is corrupt or not is known to the inspector. However, the inspector can collude with the official and refrain from revealing the corruption in exchange for side payments (similar to Tirole (1992)). We assume that the inspector can conceal a corrupt official's wrongdoing, but cannot make corruption charges on a clean official. Therefore even if we would like to use the probability of inspection as a policy variable, it is unobservable. What is observed is the actual number of corrupt officials revealed.

Throughout the paper, we assume that disciplinary inspection is effortless to the inspector. The argument that a lack of discipline is caused by a high cost of effort in inspection is straightforward but not particularly insightful, hence we shut the channel down. As a consequence, there is no wage to the inspector for the inspection job per se. However, for reasons which will become clear in Section 2.1, it is expected that in the equilibrium there will be widespread corruption. Therefore, we can specify a minimum number of corrupt officials to be delivered by the inspector. If he chooses to reveal fewer corrupt officials than required, then he will face a punishment so large that he never finds it optimal to do so.

The Organizational Structure. The organizational structure describes how the bureaucrats are organized and what type of compensation scheme is adopted in the organization. We model the organization of bureaucrats as a multi-stage tournament. More specifically, imagine a three-layer bureaucracy. There is one official at the top who is the disciplinary inspector. There are $n_{1}$ officials at the middle level who are in charge of the province-level production tasks and there are $n_{1} n_{2}$ officials at the bottom level who are in charge of the prefecture-level production tasks. The middle level officials can be thought of as the provincial governors and the bottom-level officials the prefectural mayors. Panel (a) of Figure 1 illustrates the organizational structure with a simplified example of 3 provinces and 2 prefectures per province.

\footnotetext{
${ }^{3}$ In Appendix A, we analyze 119 announcements of corruption charges published on the website of the Central Committee for Discipline Inspection of the CCP. In more than $95 \%$ of these announcements, the sacked official is described to "seek personal interests," "obtain colossal interests," "help relatives' business," "help others to get promoted," or "utilize power to seek interests." As Guo (2013) shows, this conflict-ofinterest type of corruption has become the mainstream, while cases of outright embezzlement or bribery are declining, possibly because of better auditing measures in the government.
} 
The promotion and incentive scheme is carried out as follows. At the bottom level, all $n_{2}$ prefectural mayors in the same province compete for the promotion to a provincial governor by exerting effort in the prefecture-level production. At the middle level, all $n_{1}$ provincial governors compete for the promotion to the top by exerting effort in the province-level production. The prizes of the tournament, $W_{0}, W_{1}$, and $W_{2}$, denote the (life-time) wages offered to the officials whose career ends at the top, the provincial, and the prefectural level respectively. This setup is consistent with the Chinese reality that economic or production decisions are decentralized to the officials at the lower levels of the government, but the personnel management is embodied a centralized promotion exercise based on the relative performance of officials at the same rank. In addition, the disciplinary inspection is done in a top-down fashion, which highlights the fundamental challenge that an authoritarian regime faces, namely there are no effective checks and balances at the top.

The Demographic Structure. Let's take the view of an overlapping generations model, where every generation lives for three periods, when they are young, middle-aged, and old. Assume no discounting over periods. Each generation is a continuum of citizens. Among the young citizens, a total of $n_{1} n_{2}$ ex ante identical young people are drawn to be prefectural mayors. They enter the tournament, each with private wealth $K$. They decide how much effort to spend on production, $x_{i j}$, and whether to grow their private wealth. Then, the shocks to production realize, the mayor with the highest output, $q_{i j}$, will be promoted to a provincial governor in the next period when he is middled-aged. Those lose the promotion tournament are absorbed in prefectural level non-leadership posts where they will spend their middle-aged and old periods with a lifetime wage of $W_{2}$. These losing officials also face probabilistic disciplinary inspection and if caught corrupt will lose their private wealth to the inspector. ${ }^{4}$ Among the middle-aged provincial governors, a similar process unfolds. The provincial governors choose effort, $x_{j}$, and choose whether to corrupt. Once the output $q_{j}$ realizes, the one with the highest output will be promoted to the top the next period when he is old. The losing officials exit the tournament and are absorbed in non-leadership position at the province level where he spends his old age with a lifetime wage of $W_{1}$. The losing officials then face the risk of being inspected and losing their wealth. The top of the organization is occupied by the one old agent who has won the tournament at the provincial stage, who enjoys a lifetime wage of $W_{0}$ and who inspects all contemporaneous lower-level

\footnotetext{
${ }^{4}$ In China, officials who lose the prospect of progressing to higher ranks are typically transferred to nonleadership positions at the same rank. These can be positions in the local People's Congress or local Chinese People's Political Consultative Conference among others. We assume that the losers of the tournament are absorbed in these positions at the same rank to make room for the next generation of bureaucrats in the next period.
} 
officials.

Panel (b) of Figure 1 illustrate the overlapping generations structure. Only the leadership posts which matter for promotion are shown and arrows denote the progression of career for the winning young prefectural mayors and the winning middle-aged provincial governor from period $t=1$ to $t=2$. We will solve an official's problem following his lifecycle from young to old, or from a prefectural mayor to an eventual top leader. We focus on a symmetric equilibrium, where an entering prefectural mayor will choose the same level of efforts as other prefectural mayors; and as he moves on to become a provincial governors, he will choose the same level of efforts as other provincial governors. We use 2, 1, 0 to denote the second stage of the tournament (i.e. played by young prefectural mayors), the first stage of the tournament (i.e. played by middled-aged provincial governors) and the outcome of the tournament (i.e. the realization of the old top leader). Since successive generations of officials solve exactly the same problem, we face the same cross section of officials with their incentive compatible constraints and hence the same wage contracts maximize the output net cost of incentives in each period. Because the overlapping generations are stacked up to form the same cross section every period, there is no real dynamism in this model and we therefore suppress the time argument in derivation or solution. In what follows, we first tackle the top official's problem of disciplinary inspection.

\subsection{Disciplinary Inspection Enforced by the Top Official}

We establish first the probabilities of inspection at the two lower levels of the government, under which all officials are indifferent between corrupt and not. ${ }^{5}$ Let's first consider the tradeoff faced by a prefectural mayor. Since the chance of promotion is not affected by corruption at the prefectural level nor is the continuation value of a provincial governor, he simply compares the payoff from losing as a corrupt official (i.e. the left hand side of (2)) with the payoff from losing as a clean official (i.e. the right hand side of (2)). He is indifferent between being corrupt and not corrupt if and only if the probability of inspection is $\pi_{2}^{*}$ given

\footnotetext{
${ }^{5}$ The assumption that only losing officials are inspected is not essential but simplifies the model. Another way to think about this assumption is to view the temporary immunity to inspection as part of the reward from winning - winning the prefectural level tournament does not however immune the official from being inspected at the provincial level. In Section 2.5, we consider an alternative setup where all officials, winners or losers, are subject to disciplinary inspection.
} 
by:

$$
\begin{aligned}
& W_{2}+\left(1-\pi_{2}^{*}\right) r_{2} K=W_{2}+K \\
\Rightarrow & \pi_{2}^{*}=1-\frac{1}{r_{2}} .
\end{aligned}
$$

By the same token, a losing provincial governor who was corrupt as a prefectural mayor earlier in his career is indifferent between being corrupt and not corrupt if and only if the probability of inspection is $\pi_{1}^{*}$ given by:

$$
\begin{aligned}
& W_{1}+\left(1-\pi_{1}^{*}\right) r_{1} r_{2} K=W_{1}+r_{2} K \\
\Rightarrow & \pi_{1}^{*}=1-\frac{1}{r_{1}},
\end{aligned}
$$

Notice that all provincial governors face the same trade-off regarding corruption and so are all prefectural mayors. Therefore, for officials of the same rank, either all are corrupt or none is corrupt. For simplicity, whenever an official is indifferent between being corrupt and not corrupt, we assume that he is corrupt.

We do not observe the probability of inspection implemented by the inspector, however we observe the corrupt officials the inspector chooses to reveal. Imagine we would like the inspector to inspect the losing officials at probabilities strictly higher than $\pi_{1}^{*}$ and $\pi_{2}^{*}$ to eliminate corruption. We realize, however, that there is no way to enforce these probabilities. The outcome that would be consistent with these probabilities is zero corruption charges. But then the inspector could privately lower the actual probabilities of inspection to $\pi_{1}^{*}$ and $\pi_{2}^{*}$, where all officials will be corrupt, and extort payments from the inspected officials for covering up. Given the structure of the game, it is also expected that there will be at most a proportion of $\pi_{1}^{*}$ among the losing provincial governors and $\pi_{2}^{*}$ among the losing prefectural mayors who are caught corrupt. Denote the minimum percentages of corrupt losing officials that is required from the inspector by $\left(\bar{\pi}_{1}, \bar{\pi}_{2}\right)$ and we must have $\bar{\pi}_{1} \leq \pi_{1}^{*}$ and $\bar{\pi}_{2} \leq \pi_{2}^{*}$.

Moreover, if we require the inspector to deliver $\left(\bar{\pi}_{1}, \bar{\pi}_{2}\right)$ which is strictly lower than $\left(\pi_{1}^{*}, \pi_{2}^{*}\right)$, then a rational inspector will not inspect at the lower probabilities $\bar{\pi}_{1}$ and $\bar{\pi}_{2}$. He will instead inspect the losing officials with probabilities $\pi_{1}^{*}$ and $\pi_{2}^{*}$, under which all are corrupt, and randomly choose a subset of them, $\bar{\pi}_{1}$ and $\bar{\pi}_{2}$ of the losing officials to report. In the case of a collusion, the inspector covers up corruption in exchange for side payments from the official. The inspector can ask up to the official's entire private wealth for the cover-up and we assume this is the case. This way, he can keep to himself a total of $\pi_{1}^{*}-\bar{\pi}_{1}$ of losing provincial governors' private wealth and $\pi_{2}^{*}-\bar{\pi}_{2}$ of losing prefectural 
mayors' wealth. It is only under $\bar{\pi}_{1}=\pi_{1}^{*}$ and $\bar{\pi}_{2}=\pi_{2}^{*}$ that collusion between the inspector and the inspected is eliminated. In this case, the inspector has no choice but to inspect at exactly these probabilities and report all inspected officials. If he increased the probabilities marginally, then officials would stop corrupting and he would not be able to deliver the specified minimum number of convictions. If he decreased the probabilities marginally, then he would not have enough convictions to report.

We summarize these arguments in the following proposition about the intensity of disciplinary inspection.

Proposition 1. Let the minimum percentages of convicted losing provincial governors and prefectural mayors that is required from the inspector be denoted by $\left(\bar{\pi}_{1}, \bar{\pi}_{2}\right)$.

(1) A feasible requirement must have $\left(\bar{\pi}_{1}, \bar{\pi}_{2}\right) \leq\left(\pi_{1}^{*}, \pi_{2}^{*}\right)$.

(2) If $\left(\bar{\pi}_{1}, \bar{\pi}_{2}\right)=\left(\pi_{1}^{*}, \pi_{2}^{*}\right)$, then there is no collusion between the inspector and the officials.

(3) If $\left(\bar{\pi}_{1}, \bar{\pi}_{2}\right)<\left(\pi_{1}^{*}, \pi_{2}^{*}\right)$, then there will be collusion between the inspector and some officials. More specifically, the actual probabilities of inspection implemented by the inspector are $\pi_{1}^{*}$ and $\pi_{2}^{*}$ and the inspector colludes with $\pi_{1}^{*}-\bar{\pi}_{1}$ of leaving provincial governors and $\pi_{2}^{*}-\bar{\pi}_{2}$ of leaving prefectural mayors.

From Proposition 1, it is clear that the actual probabilities of inspection that are implemented are always $\pi_{1}^{*}$ and $\pi_{2}^{*}$, regardless of the requirement imposed on the inspector. Under these probabilities, all officials are corrupt. In the case of an inspection, the official always loses all his wealth, either to be confiscated if his case is reported or to the inspector during a collusion. The result that corruption cannot be eliminated in this setting is due to the deep-rooted informational friction inherent in the inspection and the assumption that all officials are selfish (Corollary 1$).{ }^{6}$

Corollary 1. Probabilities of inspection that are high enough to eliminate corruption cannot be enforced.

In what follows, we set the probabilities of inspection that the officials face to the ones that the inspector actually implements: $\pi_{1}=\pi_{1}^{*}=1-\frac{1}{r_{1}}$ and $\pi_{2}=\pi_{2}^{*}=1-\frac{1}{r_{2}}$. These probabilities need not coincide with the minimum percentages required from the inspector, for which we maintain the notation of $\bar{\pi}_{1}$ and $\bar{\pi}_{2}$. By Proposition $1,\left(\bar{\pi}_{1}, \bar{\pi}_{2}\right) \leq\left(\pi_{1}^{*}, \pi_{2}^{*}\right)$.

\footnotetext{
${ }^{6}$ In settings where some bureaucrats are of a benevolent type and others of a selfish type, it is possible to at least temporarily eliminate corruption (Besley and Kudamatsu, 2008; Che et al., 2013).
} 


\subsection{Production Decisions Made by the Lower-Level Officials}

We consider a symmetric equilibrium of the multi-stage tournament, where all middle-aged provincial governors exert effort $x_{1}$ and all young prefectural mayors exert effort $x_{2}$. Suppose the cost of effort is quadratic, $c(x)=\frac{1}{2} \kappa x^{2}$.

The Provincial Governor's Problem. Given $\left(\bar{\pi}_{1}, \bar{\pi}_{2}\right)$, the top leader who is also the inspector expects transfers from inspected officials during a collusion. Denote these transfers as $I\left(\bar{\pi}_{1}, \bar{\pi}_{2}\right)$. Proposition 1 implies that the transfers are of the magnitude:

$$
I\left(\bar{\pi}_{1}, \bar{\pi}_{2}\right) \equiv\left(\pi_{1}^{*}-\bar{\pi}_{1}\right)\left(n_{1}-1\right) r_{1} r_{2} K+\left(\pi_{2}^{*}-\bar{\pi}_{2}\right) n_{1}\left(n_{2}-1\right) r_{2} K .
$$

For the provincial governor of province $j$, if he wins the promotion, then he will become the top official next period when he is old. Then he will get the top prize $W_{0}$, keeps his accumulated wealth $r_{1} r_{2} K$, and receives transfers as an inspector, $I\left(\bar{\pi}_{1}, \bar{\pi}_{2}\right)$. Otherwise, he is moved to a non-leadership post at the provincial level, gets a prize $W_{1}$, is inspected with probability $\pi_{1}^{*}$ in which case he loses his wealth. The problem he faces can be formulated as:

$$
\begin{aligned}
V_{1} & =\max _{x_{j}} P\left(x_{j} ; x_{1}\right)\left(W_{0}+r_{1} r_{2} K+I\left(\bar{\pi}_{1}, \bar{\pi}_{2}\right)\right)+\left(1-P\left(x_{j} ; x_{1}\right)\right)\left(W_{1}+\left(1-\pi_{1}^{*}\right) r_{1} r_{2} K\right)-c\left(x_{j}\right) \\
& =\max _{x_{j}} P\left(x_{j} ; x_{1}\right)\left(W_{0}+r_{1} r_{2} K+I\left(\bar{\pi}_{1}, \bar{\pi}_{2}\right)\right)+\left(1-P\left(x_{j} ; x_{1}\right)\right)\left(W_{1}+r_{2} K\right)-c\left(x_{j}\right),
\end{aligned}
$$

where the probability of winning is:

$$
P\left(x_{j} ; x_{1}\right)=\int_{\mathbf{R}} G\left(x_{j}-x_{1}+\eta_{j}\right)^{n_{1}-1} g\left(\eta_{j}\right) d \eta_{j},
$$

and $G(\cdot)(g(\cdot))$ is the cdf (pdf) of $\eta_{j}$. Then,

$$
\frac{\partial P\left(x_{j} ; x_{1}\right)}{\partial x_{j}}=\int_{\mathbf{R}}\left(n_{1}-1\right) G\left(x_{j}-x_{1}+\eta_{j}\right)^{n_{1}-2} g\left(x_{j}-x_{1}+\eta_{j}\right) g\left(\eta_{j}\right) d \eta_{j} .
$$

The first-order necessary condition (FONC) is

$$
\frac{\partial P\left(x_{j} ; x_{1}\right)}{\partial x_{j}}\left(W_{0}+r_{1} r_{2} K+I\left(\bar{\pi}_{1}, \bar{\pi}_{2}\right)-W_{1}-r_{2} K\right)-c^{\prime}\left(x_{j}\right)=0,
$$

which equates the marginal benefit from exerting effort, or the higher expected payoff from increasing the probability of success, with the marginal cost of exerting effort. Evaluated at 
$x_{1}$ in the equilibrium:

$$
\int_{\mathbf{R}}\left(n_{1}-1\right) G\left(\eta_{j}\right)^{n_{1}-2} g\left(\eta_{j}\right)^{2} d \eta_{j}\left(W_{0}-W_{1}+r_{1} r_{2} K-r_{2} K+I\left(\bar{\pi}_{1}, \bar{\pi}_{2}\right)\right)=\kappa x_{1} .
$$

Note that the integral, which is the marginal increase in the probability of winning from more effort, is pinned down by the distribution of the shock, $\eta_{j}$, and the number of provincial governors, $n_{1}$. To simplify notation, let $t_{1} \equiv \int_{\mathbf{R}}\left(n_{1}-1\right) G\left(\eta_{j}\right)^{n_{1}-2} g\left(\eta_{j}\right)^{2} d \eta_{j}$ and let $\Delta W_{1} \equiv$ $W_{0}-W_{1}+\left(r_{1}-1\right) r_{2} K+I\left(\bar{\pi}_{1}, \bar{\pi}_{2}\right) . \Delta W_{1}$ combines all the incentives a provincial governor faces for promotion. The FONC can be written compactly as:

$$
x_{1}=\frac{t_{1} \Delta W_{1}}{\kappa} .
$$

The value function of becoming a middle-aged provincial governor is then

$$
V_{1}=\frac{1}{n_{1}} \Delta W_{1}+\left(W_{1}+r_{2} K\right)-\frac{1}{2} \kappa x_{1}^{2}
$$

The Prefectural Mayor's Problem. For a young prefectural mayor $i$ in province $j$, if he wins the promotion, he will become a provincial governor next period when he is middleaged and will then get the provincial governor's value $V_{1}$. Otherwise, he is moved to a non-leadership post at the prefectural level, gets a prize $W_{2}$, is inspected with probability $\pi_{2}^{*}$ in which case he loses his wealth. The problem he faces can be formulated as:

$$
\begin{aligned}
V_{2} & =\max _{x_{i j}} P\left(x_{i j} ; x_{2}\right) V_{1}+\left(1-P\left(x_{i j} ; x_{2}\right)\right)\left(W_{2}+\left(1-\pi_{2}^{*}\right) r_{2} K\right)-c\left(x_{i j}\right) \\
& =\max _{x_{i j}} P\left(x_{i j} ; x_{2}\right) V_{1}+\left(1-P\left(x_{i j} ; x_{2}\right)\right)\left(W_{2}+K\right)-c\left(x_{i j}\right),
\end{aligned}
$$

where $P\left(x_{i j} ; x_{2}\right)$ is the probability that he will beat all other mayors in province $j$ :

$$
P\left(x_{i j} ; x_{2}\right)=\int_{\mathbf{R}} F\left(x_{i j}-x_{2}+\varepsilon_{i j}\right)^{n_{2}-1} f\left(\varepsilon_{i j}\right) d \varepsilon_{i j} .
$$

Here $F(\cdot)(f(\cdot))$ is the cdf (pdf) of $\varepsilon_{i j}$. Then,

$$
\frac{\partial P\left(x_{i j} ; x_{2}\right)}{\partial x_{i j}}=\int_{\mathbf{R}}\left(n_{2}-1\right) F\left(x_{i j}-x_{2}+\varepsilon_{i j}\right)^{n_{2}-2} f\left(x_{i j}-x_{2}+\varepsilon_{i j}\right) f\left(\varepsilon_{i j}\right) d \varepsilon_{i j} .
$$


The FONC is

$$
\frac{\partial P\left(x_{i j} ; x_{2}\right)}{\partial x_{i j}}\left[V_{1}-W_{2}-K\right]-c^{\prime}\left(x_{i j}\right)=0,
$$

which again equates the marginal benefit and marginal cost of exerting effort. Evaluated at $x_{2}$, it becomes:

$$
\int_{\mathbf{R}}\left(n_{2}-1\right) F\left(\varepsilon_{i j}\right)^{n_{2}-2} f\left(\varepsilon_{i j}\right)^{2} d \varepsilon_{i j}\left(V_{1}-W_{2}-K\right)=\kappa x_{2},
$$

where $V_{1}$ is given by (6). Let $\Delta W_{2} \equiv W_{1}-W_{2}+\left(r_{2}-1\right) K$ and define $t_{2}$ analogously as $t_{2} \equiv \int_{\mathbf{R}}\left(n_{2}-1\right) F\left(\varepsilon_{i j}\right)^{n_{2}-2} f\left(\varepsilon_{i j}\right)^{2} d \varepsilon_{i j}$, we have

$$
x_{2}=\frac{t_{2}}{\kappa}\left(\Delta W_{2}+\frac{1}{n_{1}} \Delta W_{1}-\frac{1}{2 \kappa} t_{1}^{2} \Delta W_{1}^{2}\right) .
$$

The second-order sufficient conditions for the provincial governor's problem and the prefectural mayor's problem are detailed in Appendix B. Throughout the paper, we assume that the second-order sufficient conditions are satisfied and interior solutions of officials' efforts are obtained. These FONCs are the incentive compatibility constraints in the problem of finding the optimal incentives, which we turn to next.

\subsection{The Optimal Set of Incentives}

At every period, officials from different generations occupy posts at various ranks of the bureaucracy. We want to find the wage scale, $\left\{W_{0}, W_{1}, W_{2}\right\}$, and the minimum fractions of corruption cases, $\left(\bar{\pi}_{1}, \bar{\pi}_{2}\right)$, to maximize the expected aggregate final output net the cost of incentives at each period. Since this problem is repeated without change every period, it is essentially a static problem:

$$
\max _{W_{0}, W_{1}, W_{2}} E\left(n_{1} n_{2} \mathcal{A} q_{1}^{\alpha} q_{2}^{\beta}\right)-W_{0}-\left(n_{1}-1\right) W_{1}-\left(n_{2}-1\right) n_{1} W_{2},
$$

subject to the incentive compatibility constraints of the provincial governors and prefectural mayors, (5) and (7). We can rewrite the problem equivalently in terms of $\Delta W_{1}, \Delta W_{2}, W_{2}$, and $\bar{\pi}_{1}, \bar{\pi}_{2}$ as follows:

$$
\begin{aligned}
\max _{\Delta W_{1}, \Delta W_{2}, W_{2}, \bar{\pi}_{1}, \bar{\pi}_{2}} \quad n_{1} n_{2} \mathcal{A} x_{1}^{\alpha} x_{2}^{\beta}-\Delta W_{1}-n_{1} \Delta W_{2}- & n_{1} n_{2} W_{2}+\left(r_{2}\left(r_{1}-1\right)\right. \\
& \left.+n_{2}\left(r_{2}-1\right)\right) K+I\left(\bar{\pi}_{1}, \bar{\pi}_{2}\right)
\end{aligned}
$$


Normalize the outside option of a losing prefectural mayor to 0 , so $W_{2} \geq 0$. Hence, we optimally set $W_{2}$ to 0 . Recall $I\left(\bar{\pi}_{1}, \bar{\pi}_{2}\right)$ from (4), which are decreasing in $\bar{\pi}_{1}$ and $\bar{\pi}_{2}$ and therefore we set $\bar{\pi}_{1}=\bar{\pi}_{2}=0$, in which case wealth from all inspected officials is transferred from the corrupt officials to the top leader. ${ }^{7}$ This is optimal as long as the social value of the confiscated asset is less than its private value to the top leader. In this case, we can rely on the inspector's income from collusion as part of the top prize at the end of the tournament and save on the top leader's explicit wage payment. Then we solve $\Delta W_{1}$ and $\Delta W_{2}$ from (5) and (7) as functions of $x_{1}$ and $x_{2}$ and plug them in the objective function, (8), which yields

$$
\begin{aligned}
\max _{\Delta W_{1}, \Delta W_{2}} n_{1} n_{2} \mathcal{A} x_{1}^{\alpha} x_{2}^{\beta}-\Delta W_{1}-n_{1}\left(\frac{\kappa}{t_{2}} x_{2}\right. & \left.-\frac{1}{n_{1}} \Delta W_{1}+\frac{1}{2} \kappa x_{1}^{2}\right) \\
& +n_{1}\left(r_{2}\left(r_{1}-1\right)+n_{2}\left(r_{2}-1\right)\right) K \\
\Leftrightarrow \max _{x_{1}, x_{2}} \quad n_{1} n_{2} \mathcal{A} x_{1}^{\alpha} x_{2}^{\beta}-n_{1} \frac{1}{t_{2}} \kappa x_{2}-n_{1} \frac{1}{2} \kappa x_{1}^{2} & +n_{1}\left(r_{2}\left(r_{1}-1\right)+n_{2}\left(r_{2}-1\right)\right) K
\end{aligned}
$$

This is a concave objective in two choice variables (Appendix B). The FONCs for $x_{1}$ and $x_{2}$ are both necessary and sufficient:

$$
\left\{\begin{array}{l}
n_{1} n_{2} \mathcal{A} \alpha x_{1}^{\alpha-1} x_{2}^{\beta}=n_{1} \kappa x_{1} \\
n_{1} n_{2} \mathcal{A} x_{1}^{\alpha} \beta x_{2}^{\beta-1}=n_{1} \frac{\kappa}{t_{2}}
\end{array} .\right.
$$

We can easily solve out the efforts elicited under the optimal incentive scheme:

$$
\begin{aligned}
& x_{1}^{*}=\left(\alpha^{1-\beta} \beta^{\beta} n_{2} \mathcal{A} t_{2}^{\beta} \kappa^{-1}\right)^{\frac{1}{2-\alpha-2 \beta}} \\
& x_{2}^{*}=\left(\alpha^{\alpha} \beta^{2-\alpha} n_{2}^{2} \mathcal{A}^{2} t_{2}^{2-\alpha} \kappa^{-2}\right)^{\frac{1}{2-\alpha-2 \beta}} .
\end{aligned}
$$

The optimal efforts are functions of parameters of the production function $(\alpha, \beta$, and $\mathcal{A})$, the tournament $\left(n_{2}\right.$ and $\left.t_{2}\right)$, and the cost function $(\kappa)$. An examination of the transformation of the objective function from (8) to (9) reveals that the cost of incentive to the provincial governors, $\Delta W_{1}$, is canceled out in our objective function. In other words, if we structure a bigger incentive to the provincial governors, then this incentive will show up as the continuation value of the prefectural mayors, and hence substitute for the wage incentive to the prefectural mayors. The effects of $\Delta W_{1}$ at the provincial and the prefectural level completely cancel out and do not affect the total cost of incentives.

\footnotetext{
${ }^{7}$ The existence of collusion income at the top office is not essential in the baseline model. Even if we set $\bar{\pi}_{1}=\pi_{1}^{*}$ and $\bar{\pi}_{2}=\pi_{2}^{*}$ so as to eliminate collusion, the equilibrium optimal wage scale will be concave in this tournament.
} 
An examination of (9) shows that there is no distortion in the elicitation of effort at the provincial level in the sense that the social cost of $x_{1}$ is the same as the sum of the private costs of $x_{1}$ to the relevant agents: $n_{1} \frac{1}{2} \kappa x_{1}^{2}$. However, the limited liability constraint $W_{2} \geq 0$ distorts the cost of effort at the prefectural level. The cost of eliciting $x_{2}$ then depends not only on the cost parameter $\kappa$, but also on how sensitive the probability of promotion is to effort, $t_{2}$, which in turn depends on the number of contestants, $n_{2}$, and the amount of luck, $\sigma_{2}^{2}$. Another way of saying it is that the two-stage tournament is effectively reduced to a rank-order tournament at the prefectural level only, while at the provincial level it is as if we can contract directly on effort. ${ }^{8}$ This is the reason why the optimally chosen $x_{1}^{*}$ and $x_{2}^{*}$ only depend on the parameters of the tournament at the prefectural level.

The total incentives given to a provincial governor and a prefectural mayor are then given by,

$$
\begin{aligned}
& \Delta W_{1}^{*}=\frac{\kappa}{t_{1}}\left(\alpha^{1-\beta} \beta^{\beta} n_{2} \mathcal{A} t_{2}^{\beta} \kappa^{-1}\right)^{\frac{1}{2-\alpha-2 \beta}} \\
& \Delta W_{2}^{*}=\frac{\kappa}{t_{2}}\left(\alpha^{\alpha} \beta^{2-\alpha} n_{2}^{2} \mathcal{A}^{2} t_{2}^{2-\alpha} \kappa^{-2}\right)^{\frac{1}{2-\alpha-2 \beta}}-\frac{1}{n_{1}} \Delta W_{1}^{*}+\frac{1}{2 \kappa} t_{1}^{2} \Delta W_{1}^{* 2} .
\end{aligned}
$$

Note that $x_{1}^{*}, x_{2}^{*}, \Delta W_{1}^{*}$, and $\Delta W_{2}^{*}$ are all pinned down by the parameters that characterizes production technologies, shocks and the organizational structure. The net output, that is the total output minus the cost of incentive, can be written in terms of the exogenous parameters:

$$
\Pi^{*}=n_{1} n_{2} \mathcal{A} x_{1}^{* \alpha} x_{2}^{* \beta}-\Delta W_{1}^{*}-n_{1} \Delta W_{2}^{*}+n_{1}\left(r_{2}\left(r_{1}-1\right)+n_{2}\left(r_{2}-1\right)\right) K .
$$

We summarize the optimal incentive scheme in Proposition 2.

Proposition 2. The optimal wage contract, $\left\{W_{0}, W_{1}, W_{2}\right\}$, offered to the government offi-

\footnotetext{
${ }^{8}$ More generally, if there are $m$ stages in the tournament, then the $m$-stage sequential-elimination rankorder tournament can be reduced to a single-stage rank-order tournament at the $m$ th stage, whereas at all further stages we can effectively contract on effort. However, if we allow the wage to the lowest level losing official to be negative, which effectively serves as an entry ticket to the tournament, then it is possible to elicit the first-best efforts from all officials. Note that since we assume risk-neutrality of all in what is effectively a principal-agent problem, we abstract away from the incentive insurance trade-off between the principal and agents.
} 
cials satisfies:

$$
\begin{aligned}
& W_{2}=0 \\
& W_{1}=\Delta W_{2}^{*}-\left(r_{2}-1\right) K \\
& W_{0}=\Delta W_{1}^{*}+W_{1}-\left(r_{1}-1\right) r_{2} K-I(0,0),
\end{aligned}
$$

where

$$
I(0,0)=\left(\left(n_{1}-1\right)\left(r_{1}-1\right) r_{2}+n_{1}\left(n_{2}-1\right)\left(r_{2}-1\right)\right) K
$$

and where $\Delta W_{1}^{*}$ and $\Delta W_{2}^{*}$ are given by (12) and (13). The efforts elicited from the provincial governors, $x_{1}^{*}$, and from the prefectural mayors, $x_{2}^{*}$, are given by (10) and (11). The maximized net output is given by (14).

\subsection{Discussions}

Now we are in the position to examine how the wage incentive interacts with the implicit corruption incentives.

\subsubsection{Relationship to Tournament Incentives}

First of all, to put our results in the perspective of the literature on tournament labor contracts, we show that when all incentives, explicit and implicit, are considered, our model does imply a convex incentive structure as previously established by Rosen (1986). To see this, we prove that a special parametrization of our model, which is consistent with the setup of Rosen (1986), delivers its key prediction, namely a disproportionately large prize at the top. Recall that the prizes $\Delta W_{1}$ and $\Delta W_{2}$ are total incentives that officials face, which include the explicit wages as well as the corruption income from holding the offices, and in the case of the inspector, the collusion income.

Corollary 2. Suppose $n_{1}=n_{2}=2, t_{1}=t_{2}=t$, and $x_{1}^{*}=x_{2}^{*}=x^{*}$. Under these conditions, the equilibrium of our model is equivalent to a symmetric equilibrium of a sequential elimination tournament in pairs considered by Rosen (1986). Then, we have

$$
\Delta W_{1}^{*}>\Delta W_{2}^{*}
$$

as long as the the no-default condition in Rosen (1986) holds. 
Suppose $n_{1}=n_{2}=2, t_{1}=t_{2}=t$, and $x_{1}=x_{2}=x^{*}$. Then from (5) and (7), we have

$$
\begin{aligned}
\Delta W_{1}^{*} & =\frac{\kappa}{t} x^{*} \\
\Delta W_{2}^{*} & =\frac{\kappa}{2 t} x^{*}+\frac{\kappa}{2} x^{* 2} .
\end{aligned}
$$

Therefore, $\Delta W_{1}^{*}>\Delta W_{2}^{*}$ is equivalent to $t<\frac{1}{x^{*}}$. Note that in a Tullock style contest as in Rosen's original paper, the probability of winning is of the functional form, $\operatorname{Pr}(i$ wins $)=$ $\frac{h\left(x_{i}\right)}{h\left(x_{i}\right)+h\left(x_{j}\right)}$, where $x_{i}$ is the contestant's effort, $x_{j}$ is the opponent's effort, and $h(x)$ is some increasing function. Then, the marginal increase in the probability of winning evaluated at the symmetric equilibrium becomes $\left.\frac{\partial \operatorname{Pr}(i \text { wins })}{\partial x_{i}}\right|_{x_{i}=x^{*}, x_{j}=x^{*}} \equiv t=\frac{h^{\prime}\left(x^{*}\right)}{4 h\left(x^{*}\right)}$. On the other hand, note that $\frac{1}{x^{*}}=\frac{c^{\prime}\left(x^{*}\right)}{2 c\left(x^{*}\right)}$. Therefore, the condition for a bigger top incentive $\Delta W_{1}^{*}>\Delta W_{2}^{*}$ can be rewritten as $\frac{h^{\prime}\left(x^{*}\right)}{4 h\left(x^{*}\right)}<\frac{c^{\prime}\left(x^{*}\right)}{2 c\left(x^{*}\right)}$, or $\frac{x^{*} h^{\prime}\left(x^{*}\right) / h\left(x^{*}\right)}{x^{*} c^{\prime}\left(x^{*}\right) / c\left(x^{*}\right)}<2$, which is exactly the no-default condition in Rosen (1986). ${ }^{9}$

This example shows that if we keep the degree of competition $\left(n_{i}\right.$ and $\left.t_{i}\right)$ and the targeted effort level $\left(x_{i}\right)$ constant across the ranks of the tournament, as long as the no-default condition holds, the optimal prize design must have a big top prize.

In our model, the number of contending officials per promotion, the size of shocks, and the desired level of effort may differ across ranks, which induces differences in required incentives given to the officials to rise through the ranks. Corollary 2 however confirms that our model inherits the essential feature of an elimination tournament type of incentive scheme, that all else equal, it is more costly to elicit effort as the officials get closer to the top. As the explicit wage scale does not appear convex at all, we posit that the difference between the required incentives and the wages is then explained by wealth accumulation from rent-seeking activities. Moreover, such difference increases as the officials rise through the ranks, as the the wealth grows exponentially. We turn to this observation next.

\subsubsection{The Wealth Accumulation Effect}

As we have pointed out earlier in Section 2.2, the total incentives needed for an efficient level of efforts are determined by the technologies, the shocks and the organizational structure (see $\Delta W_{1}^{*}$ and $\Delta W_{2}^{*}$ in (12) and (13)). Observe, however, what makes up for these incentives is not only wage payment, but also own cumulated corruption-tainted assets as well as inspector's income from collusion, which is the inspected officials' cumulated corruption-

\footnotetext{
${ }^{9}$ The no-default condition rules out the cases in which the elasticity of response of effort, $x^{*} h^{\prime}\left(x^{*}\right) / h\left(x^{*}\right)$, is too large relative to the elasticity of its cost, $x^{*} c^{\prime}\left(x^{*}\right) / c\left(x^{*}\right)$. In those cases, contestants' efforts to win drive the payoff to each below zero and they do better by defaulting or exerting zero effort.
} 
tainted assets. Rewrite the prizes in Proposition 2 as

$$
\begin{aligned}
\Delta W_{2}^{*} & =W_{1}-W_{2}+\left(r_{2}-1\right) K \\
\Delta W_{1}^{*} & =W_{0}-W_{1}+\left(r_{1}-1\right) r_{2} K+I(0,0) \\
& =W_{0}-W_{1}+n_{1}\left(\left(r_{1}-1\right) r_{2}+\left(n_{2}-1\right)\left(r_{2}-1\right)\right) K .
\end{aligned}
$$

The explicit wage incentives are given by $W_{1}-W_{2}$ for prefectural mayors and $W_{0}-W_{1}$ for provincial governors. It is clear that wages only provide partial incentives, the other part of incentives come from two sources. The first is the value of keeping own corruptiontainted assets due to temporary immunity from inspection, $\left(1-\pi_{2}^{*}\right) r_{2} K=\left(r_{2}-1\right) K$ for the prefectural mayors and $\left(1-\pi_{1}^{*}\right) r_{1} r_{2} K=\left(r_{1}-1\right) r_{2} K$ for the provincial governor. The second is the extra source of income of the top leader as the disciplinary inspector, $I(0,0)$.

For a given required level of total incentive, $\Delta W_{1}^{*}$ and $\Delta W_{2}^{*}$, the bigger the $K$ the less progressive the wage scale appears:

$$
\begin{aligned}
\left(W_{0}-W_{1}\right)-\left(W_{1}-W_{2}\right) & =\Delta W_{1}^{*}-\Delta W_{2}^{*}-\left(\left(r_{1}-1\right) r_{2}-\left(r_{2}-1\right)\right) K-I(0,0) \\
& =\Delta W_{1}^{*}-\Delta W_{2}^{*}-\left[n_{1}\left(r_{1}-1\right) r_{2}+\left(n_{1}\left(n_{2}-1\right)-1\right)\left(r_{2}-1\right)\right] K .
\end{aligned}
$$

Note that $n_{1}\left(r_{1}-1\right) r_{2}+\left(n_{1}\left(n_{2}-1\right)-1\right)\left(r_{2}-1\right) \geq 0$, since $r_{1}, r_{2}>1$ and $n_{1}, n_{2} \geq 2$. Therefore, the difference in pay differences across two consecutive ranks, or the speed at which pay rise increases, is declining in $K$. We have the following result.

Corollary 3. The bigger the private wealth endowment of the officials, $K$, the lower powered the wage scale appears.

Corollary 3 reconciles a seemingly low-powered pay scale in the public sector in China with a tournament-style compensation scheme that calls for a grand prize at the end of the tournament. The grand prize above the mildly higher wage of the top leader is composed of the security of own cumulated assets and the transfer of inspected officials' cumulated assets. This multi-stage tournament scheme leverages on the corruption-tainted private wealth accumulation of the officials to economize on the cost of incentives. It is easy to extend this model to tournaments that last more than two stages (Section 3).

More broadly, such an incentive scheme may be attractive at an early development stage, when the state's capacity to collect tax is limited so that there is only a limited budget to fund the wages of government officials. In this model, if none of the officials are endowed with any capital $(K=0)$ or there is no corruption opportunities $\left(r_{i}=0, \forall i\right)$, then the efficient 
levels of production must be incentivized by $W_{1}=\Delta W_{2}^{*}$ for each provincial governor and

$W_{0}=W_{1}+\Delta W_{1}^{*}$ for the top leader, which may well exceed the revenue of a poorly funded government.

Last but not the least, we have focused on the puzzle of the seemingly low wage incentives in one of the most successful tournament style incentive schemes in practice, one that is adopted to incentivize Chinese officials to promote economic growth. We however do not intend to, nor are we able to, comment on the welfare properties of this incentive system. Doing so would require us to model formally the social cost of the rent-seeking behavior, which we leave for future research. In Section 3.3, we will come back to this idea that the rent-seeking behavior interfere with the production side of the economy.

\subsection{Further Discussions on the Institutional Setup}

We discuss here two assumptions we make to the institutional setup. The first is the assumption that the promotion criterion is based on achieving the highest output. The second is the assumption that disciplinary inspection is only imposed on officials who are not promoted.

The Promotion Criterion In the baseline model, it is assumed that the promotion is based on performance in terms of the outcome of the official's task at his level, $q_{j}$ for provincial governors and $q_{i j}$ for prefectural mayors. The top performer among his peers is promoted. This promotion criterion is a natural one from the point of view of the objective to maximize output, but one might wonder if the officials are willing to sign up to such a promotional regime. Given the structure of our model, the answer is yes. Imagine any alternative promotional regime that systematically pick non-top performers. Then any one official will attempt to undercut another official by an epsilon of effort, which results in a collapse of efforts at zero. Since it is perfectly foreseeable that the equilibrium efforts from officials across all ranks would be zero under such a scheme, there would be no need for wage incentives or in fact no need for the employment of the officials in the first place. As long as the expected return from participating the baseline tournament is positive, any official would prefer the baseline to the alternative outlined here. We however abstract away from different types or abilities of officials, in which case promotional regime will have bearings on the selection on types, as in Che et al. (2014).

The Subjects of the Disciplinary Inspection In the baseline model, we assume that only losers are inspected. Here we assume that all lower-level officials are subject to the disciplinary inspection and whenever one is found corrupt, he loses his private wealth. This creates a situation where the prefectural mayor who achieves the highest output is inspected, 
loses all his private wealth, and therefore progresses to become a provincial governor with zero wealth in the next period. Mathematically, we need to define a value function for the provincial governor who is not inspected at the prefectural level, $V_{1}^{c, n i}$, and a value function for the provincial governor who is inspected at the prefectural level, $V_{1}^{c, i}$ :

$$
\begin{gathered}
V_{1}^{c, n i}=\max _{x_{j}} P\left(x_{j} ; x_{1}\right)\left(W_{0}+\bar{I}\left(\bar{\pi}_{1}, \bar{\pi}_{2}\right)+\left(1-\pi_{1}^{*}\right) r_{1} r_{2} K\right)+\left(1-P\left(x_{j} ; x_{1}\right)\right)\left(W_{1}\right. \\
\left.+\left(1-\pi_{1}^{*}\right) r_{1} r_{2} K\right)-c\left(x_{j}\right) ; \\
V_{1}^{c, i}=\max _{x_{j}} P\left(x_{j} ; x_{1}\right)\left(W_{0}+\bar{I}\left(\bar{\pi}_{1}, \bar{\pi}_{2}\right)\right)+\left(1-P\left(x_{j} ; x_{1}\right)\right) W_{1}-c\left(x_{j}\right) .
\end{gathered}
$$

The prefectural mayor's value function is then given by

$$
V_{2}=\max _{x_{i j}} P\left(x_{i j} ; x_{2}\right)\left(\left(1-\pi_{2}^{*}\right) V_{1}^{c, n i}+\pi_{2}^{*} V_{1}^{c . i}\right)+\left(1-P\left(x_{i j} ; x_{2}\right)\right)\left(W_{2}+\left(1-\pi_{2}^{*}\right) r_{2} K\right)-c\left(x_{i j}\right) .
$$

In Appendix D, we show that $\pi_{1}^{*}=1-\frac{1}{r_{1}}$ and $\pi_{2}^{*}=1-\frac{1}{r_{2}}$ are still the probabilities of inspection implemented in the equilibrium, under which officials are indifferent between corrupt and not corrupt and the equilibrium efforts of all officials under the optimal wage contract are the same as those in the baseline model. The main deviation from the baseline model is that the security to keep own accumulated private wealth can no longer be part of the incentive for the top leadership, since promotion does not grant temporary immunity from inspection for lower-level officials any more. To see this point, the optimal wage scale in this setting is:

$$
\begin{aligned}
& W_{2}=0 \\
& W_{1}=\Delta W_{2}^{*} \\
& W_{0}=\Delta W_{1}^{*}+W_{1}-\bar{I}(0,0),
\end{aligned}
$$

where the collusion income made by the inspector is now $\bar{I}(0,0)=n_{1}\left(n_{2}\left(r_{2}-1\right)+r_{1}-1\right) K$ and $\Delta W_{1}^{*}$ and $\Delta W_{2}^{*}$ are the same as those in the baseline. The progressivity of the wage scale is:

$$
\begin{aligned}
W_{0}-W_{1}-\left(W_{1}-W_{2}\right) & =\Delta W_{1}^{*}-\Delta W_{2}^{*}-\bar{I}(0,0) \\
& =\Delta W_{1}^{*}-\Delta W_{2}^{*}-n_{1}\left(n_{2}\left(r_{2}-1\right)+r_{1}-1\right) K .
\end{aligned}
$$

Comparing (16) to (15), we notice two differences. First, relative to the baseline model, equal probability of inspection to all lower-level government officials provides an extra implicit top 
prize of the magnitude $n_{1}\left(r_{2}-1\right)\left(2+\frac{1}{n_{1}}-r_{1}\right) K .{ }^{10}$ Second, the gain from collusion accrued to the top leader in the role of the disciplinary inspector is present in both the baseline and in this new setting. However, the magnitude of such gain differs. At the end of the day, equation (17) clearly shows that even in this new setting, the progressivity of the wage scale decreases in $K$, a key message that is robust to the assumption of who are subject to disciplinary inspection.

\section{Mapping to China}

In this section, we calibrate an extension of the model in Section 2 to tie it closer to the Chinese context. In reality, the Chinese government broadly consists of five levels: center, province, prefecture, county, and lastly township and village level. In this simulation exercise, we consider a four-level government from county level up to the central level. It is plausible to view county-level job as an entry job to the country's bureaucratic ladder. On the data part, county-level output is the most disaggregated macro data that is available.

To extend our model to four levels of government hierarchy, we suppose that, under the central government, there are $n_{1}$ provinces; each province has $n_{2}$ prefectures; and each prefecture has $n_{3}$ counties. The county-level production function is defined analogously to $(1)$ :

$$
y_{h i j}=\mathcal{A} q_{j}^{\alpha} q_{i j}^{\beta} q_{h i j}^{\gamma}, \quad \text { with } \alpha+\beta+\gamma<1
$$

where $q_{j}$ is the output of the provincial task, $q_{i j}$ that of the prefectural task, and $q_{h i j}$ the county-level task. Similarly, denote the corresponding levels of efforts by the officials as $x_{j}$, $x_{i j}$, and $x_{h i j}$ and the corresponding levels of the luck component in the production as $\eta_{j}, \varepsilon_{i j}$ and $\zeta_{\text {hij. }}{ }^{11}$

We start by describing the data that help us pin down some key parameters of the model in Section 3.1. We present the results from the simulation in Section 3.2. In Section 3.3, we introduce another complication to the model, where we allow the rates at which private wealth accumulates to depend on the effort in public good production. By doing so, we introduce another trade-off that the officials face: The provision of public good may come

\footnotetext{
${ }^{10}$ In this setup, the implicit component of the top prize is $n_{1}\left(n_{2}\left(r_{2}-1\right)+r_{1}-1\right) K$, while in the baseline it is $\left(n_{1}\left(r_{1}-1\right) r_{2}+\left(n_{1}\left(n_{2}-1\right)-1\right)\left(r_{2}-1\right)\right) K$. Taking the difference, we get $n_{1}\left(r_{2}-1\right)\left(2+\frac{1}{n_{1}}-r_{1}\right) K$. This difference is positive if and only if $r_{1}<2+\frac{1}{n_{1}}$, which is satisfied in the parametrization of our simulations. In other words, if the scope for rent-seeking is not exceedingly high, the wage scale in this setup will appear even more concave than that in the baseline model.

${ }^{11}$ The derivation of this extended model with exogenous rates of return is found in Appendix C.2.
} 
at a cost of rent extraction.

\subsection{Data}

We obtain county-level annual output data from 1997 to 2007 and province-level consumer price indices from 1997 to 2007 to compute county-level real output growth from 1998 to 2007. We exclude from the analysis sample Beijing, Tianjin, Shanghai and Chongqing, the four municipalities directly controlled under the central government, since the internal municipal government structure is somewhat different than those in other provinces. After trimming the outliers of output growth rate to control for data entry errors, we take the average of the annual real growth of a county within the sample period. This gives us 2,613 counties in 274 prefectures and 25 provinces. ${ }^{12}$ Let the output, $y_{h i j}$, denote a county $h$ in prefecture $i$ and province $j$. According to our model,

$$
\begin{aligned}
\ln y_{h i j} & =\ln \mathcal{A}+\alpha \ln q_{j}+\beta \ln q_{i j}+\gamma \ln q_{h i j} \\
& =\ln \mathcal{A}+\alpha \ln x_{j}+\beta \ln x_{i j}+\gamma \ln x_{h i j}+\alpha \ln \eta_{j}+\beta \ln \varepsilon_{i j}+\gamma \ln \zeta_{h i j}
\end{aligned}
$$

This motivates the following series of regressions. First, we regress the county-level growth on a constant and province dummies, ProvDummy :

$$
\ln y_{h i j}=\text { constant }+\sum_{j} b_{j} \text { ProvDummy } y_{j}+u_{h i j}
$$

Denote the predicted value of $\log$ growth as $\overline{\ln y_{j}}$. Then take the residual and further regress the residuals on a constant and prefecture dummies, PrefDummy D :

$$
u_{h i j}=\text { constant }+\sum_{i, j} b_{i j} \text { PrefDummy } y_{i j}+v_{h i j} .
$$

Denote the predicted value of the above regression as $\overline{\ln y_{i j}}$. These two regressions provide a decomposition of the variance of log county growth into a province-, a prefecture- and a county-component:

$$
\begin{aligned}
\operatorname{var}\left(\ln y_{h i j}\right) & =\operatorname{var}\left(\overline{\ln y_{j}}\right)+\operatorname{var}\left(\overline{\ln y_{i j}}\right)+\operatorname{var}\left(v_{h i j}\right) \\
& =\alpha^{2} \operatorname{var}\left(\ln \eta_{j}\right)+\beta^{2} \operatorname{var}\left(\ln \varepsilon_{i j}\right)+\gamma^{2} \operatorname{var}\left(\ln \zeta_{h i j}\right) .
\end{aligned}
$$

\footnotetext{
${ }^{12}$ Detailed description of the data, sample selection, and regression results are in Appendix C.1.
} 
Given a choice of $(\alpha, \beta, \gamma)$, we can back out the variance of the logged shocks, $\sigma_{1}^{2}, \sigma_{2}^{2}$ and $\sigma_{3}^{2}$ from the between-province, within-province but between-county and within-county components of the total variance from the data.

Having implemented the regressions with our data, we find that the average total variance of county-level annual growth is 0.00255443 , of which $11.8 \%$ comes from the betweenprovince variance $(0.0003011), 20.7 \%$ from the within-province yet between-county variance (0.0005289), and $67.5 \%$ from the within-county variance $(0.0017244)$.

\subsection{Simulation}

We parametrize the model as in Table 1. In the model with exogenous rates of return on officials' private wealth, all parameters are given in Panel (a) of Table 1. The number of competitors per position respects the proportions of the number of provinces, prefectures, and counties in the analysis sample: 25 provinces, 274 prefectures (or roughly 10 per province), and 2,613 counties (or roughly 10 per prefecture). The values of the shape parameters in the county production function, $\alpha, \beta$ and $\gamma$, capture the idea that for the county output, inputs at the county and prefecture level may be more relevant than broad schemes drafted at the province level. The variance of the luck component in the competition is obtained from regressing county-level output data as detailed in Section 3.1. The TFP parameter in the county production function, $\mathcal{A}$, determines the scale of efforts, $x_{i}$ 's, which will in turn determine the scale of the output, interpreted as local economic growth. Therefore, $\mathcal{A}$ is calibrated so that the average output, $\mathcal{A} x_{1}^{* \alpha} x_{2}^{* \beta} x_{3}^{* \gamma}$, is 1.13 , or $13 \%$ annual growth rate, the average real growth observed in the data. The wealth of a county official that enters the political tournament, $K$, determines the scale of the wages. The cost of effort parameter, $\kappa$, is chosen such that the second order conditions of officials' problems are satisfied. The exogenous rates of return, $r_{1}, r_{2}$ and $r_{3}$, are such that higher political positions are more lucrative for growing private wealth. The parameter $\delta$ is introduced to normalize the collusion income by the scale of the bureaucracy: $\delta=\frac{1}{n_{1} n_{2} n_{3}} \cdot 13$

The simulation yields an optimal wage scale of $W_{3}=0, W_{2}=2.5935, W_{1}=7.7752, W_{0}=$ 10.1609. Examine the wage increments faced by an official who rises from a county post to a province post: $\Delta W_{3}=W_{2}-W_{3}=2.5935, \Delta W_{2}=W_{1}-W_{2}=5.1817$, and $\Delta W_{1}=$ $W_{0}-W_{1}=2.3857$. This gives us $\Delta W_{1}: \Delta W_{2}: \Delta W_{3}=2.3857: 5.1817: 2.5935=1$ : $1.998: 1.087$. These wage increments appear rather low-powered, especially at the top. To find the empirical counterpart of the wage scale, we calculate the life-time wage income of

\footnotetext{
${ }^{13}$ More specifically, in the simulation the collusion income to the inspector is $I=$ $\left.\delta\left[\left(n_{1}-1\right)\left(r_{1}\right) r_{2} r_{3}+n_{1}\left(n_{2}-1\right)\left(r_{2}-1\right)\right) r_{3}+n_{1} n_{2}\left(n_{3}-1\right)\right] K$ (see Appendix C.2).
} 
officials whose career culminate at the rank of county, prefecture, province and center, based on the "3581" wage scale discussed in the introduction (Appendix C.4). We find that the increments of lifetime wage income between ranks of the Chinese officials follow a similar proportion of $1: 1.9: 1.3$, which also features a very weakly powered wage scale especially at the top.

The corresponding effort levels of the provincial, prefectural, and county heads in the simulated model are $x_{1}=0.1217, x_{2}=0.2059, x_{3}=0.0406$. The prefectural mayors work the hardest, followed by the provincial governors, while the county heads work the least. This is intuitive. First, since the county heads are offered at least $W_{3}=0$ under the binding limited liability constraint, together with the fact that with multiple competitors $\left(n_{3}=10\right)$ and large noise $\left(0.0017244 / \gamma^{2}\right)$, the probability of winning at the prefectural stage is the lowest among all stages, the county head thus tend to shirk. Second, due to the interdependence of production, low effort at the county level reduces marginal product of effort at higher levels of government, and hence reduces the demand for effort at higher levels of government. Third, between the provincial governor and the prefectural leader, prefectural output weighs slightly more than provincial output in aggregate production $(\alpha=0.2$ and $\beta=0.3)$. Therefore, it's more efficient to elicit more effort from the prefectural mayors than from the provincial governors.

Next we perform a comparative statics exercise in terms of the private wealth endowment of the county heads, $K$. We vary $K$ from 8 to 10 . The results are found in Figure 2. Consistent with Corollary 3, as the private wealth endowment of the officials increase, the interest from staying in the tournament and accumulating wealth will work as an implicit compensation, and hence relieving the burden of incentivizing efforts by wages. The top prize, or $W_{0}$, decreases sharply as wealth endowment increases. Wages at lower levels also decrease as one increases $K$. The explicit wage scale looks increasingly low-powered as the implicit compensation becomes more important. The two forms of compensation, the implicit reward from wealth accumulation and the explicit wage payment, exactly cancel out to elicit a same level of effort from the officials throughout the ranks. The effort inputs and the county average growth rate stay constant.

\subsection{Endogenous Rates of Return}

It is conceivable that there might be conflict of interest as officials exert effort to produce

public good, which affects the scope of his rent seeking. For example, when deciding to whom to award a government procurement contract, the official may face the trade-off that the best bid comes from the market and not from a company that has ties to his own family. 
To capture this trade-off, we modify the above model slightly to make the rate of return on private wealth depend on the effort of producing public good. More specifically, let $r_{i}\left(x_{i}\right)$ be defined as

$$
r_{i}\left(x_{i}\right)=\bar{r}_{i}-\frac{1-e^{-\lambda x_{i}}}{1+e^{-\lambda x_{i}}}\left(\bar{r}_{i}-\underline{r}_{i}\right)
$$

Note that the rate of return $r_{i}$ is decreasing in the effort of the official $x_{i}$, so that when deciding on how much public good to produce, the official not only weighs the cost of effort against winning the tournament, but also factors in cost of reduced rates of private wealth accumulation against winning.

The parameters of the function of the rates of return (18) are found in Panel (b) of Table 1. The highest rates of return at the province, prefecture, and county level are targeted to match those in the previous model with exogenous rates of return. As the effort increases, the rates can decline to a mere $5 \%$ return. The parameter $\lambda$ governs how fast the rates decline in effort. We consider a range of $\lambda$, from 0 (i.e. equivalent to the model with exogenous rates) to 4 . The rest of the model is parametrized in the same way as in Panel (a) of the same table. The results are found in Figure $3 .^{14}$

First, we confirm that when $\lambda$ is 0 , the model reverts to the exogenous rate of return case. As $\lambda$ increases, the conflict of interest between private accumulation and public good production becomes more acute. From the point of view of the officials, the higher the $\lambda$, the more rapidly the scope for private rent-seeking dissipates, and the more progressive the wage scale needs to be to compensate officials for their efforts. This is confirmed both in Panel (c) where equilibrium rates of returns under the optimal wage scheme decrease in $\lambda$ and in Panel (a) where the optimal wage scale becomes increasingly high powered. From the point of view of maximizing net output, since the accumulation of private wealth becomes a less important form of incentive, officials' effort supply is more elastic to wage incentive, hence making it a more effective tool to elicit effort. This is especially so for the provincial governors who, in a tournament, are close to winning the top prize. The simulation result confirms this point that we optimally exploit a higher powered wage scale to induce the provincial governors to work more (Panel (b)), which ultimately leads to higher growth as $\lambda$ increases (Panel $(d)$ ). In our simulation, the wage component accounts for less than $20 \%$ of the total incentive for a provincial governor to become the top leader when $\lambda=0$, but this fraction increases to $54 \%$ when $\lambda=4$.

This exercise illustrates that the optimal wage scale must respond to all the trade-offs

\footnotetext{
${ }^{14}$ The derivation of this extended model with endogenous rates of return is found in Appendix C.3.
} 
officials face when making decisions about production. In an environment where officials trade off rent-seeking against promoting economic growth, the optimal wage scale will again need to be high-powered. The overall reduced reliance on wealth accumulation as a career incentive improves our ability to elicit effort by posting high wage at the top position. Interestingly, the overall effect on growth from considering such a trade-off is positive.

\section{Concluding Remarks}

In this article, we derive the optimal wage scale of a tournament-style labor contract in the context of the Chinese bureaucracy. Our model is consistent with two essential features of the Chinese institution: one, economic decision making is decentralized to local governments; and two, disciplinary inspection is carried out in a top-down fashion. We explicitly model the informational frictions that challenge the incentive provision to officials at various ranks to work hard to promote local economic growth. We reconcile the prima facie contradiction between a rank-order tournament incentive scheme and a low-powered public-sector pay scale in the Chinese context. The key insight is to recognize that the inability to eliminate corruption in a bureaucracy without institutionalized checks and balance paradoxically provides a form of implicit incentive in such a tournament. The official's private wealth that is built by exploiting political rents along their career is only secure when he rises to the top. In addition, centralized disciplinary inspection also provide the top leader an additional source of collusion income. These components combine to the grand prize at the end of the tournament. This incentive structure can be especially effective at an early stage of development, when the state's taxing power is limited and hence faces a tight budget constraint to offer explicit wage compensations as incentive.

Looking forward, we make several conjectures based on the insight from this model. As the government function evolves from direct participating in resource allocation to safeguarding market practices, the space for rent-seeking may diminish. This would imply changes in the public-sector pay structure. Leaving aside the potential changes on the way production in the public sector takes place, explicit wage payment would have to be increased to take the place of implicit reward from keeping corruption income. Our simulation exercise also suggests that being able to use the wage progression as the main form of incentive can be good for growth.

More generally, this article sheds light on the subtle role that corruption plays in tournament schemes, or bureaucracies where law/contract enforcement is also embedded in the same hierarchical structure. For many developing countries, corruption and the lack of the 
rule of law (in the sense of an independent judiciary system) are two perennial institutional problems, which lead to long-term poverty and political instability. The mechanism in this paper however illustrates how the two can coexist in a stable equilibrium in the Chinese historical context. 


\section{References}

Banerjee, A. V. (1997). A theory of misgovernance. Quarterly Journal of Economics, 112:1289-1332.

Becker, G. S. and Stigler, G. J. (1974). Law enforcement, malfeasance and the compensation of enforcers. Journal of Legal Studies, 3(1):1-18.

Besley, T. and Kudamatsu, M. (2008). Making autocracy work. In Helpman, E., editor, Institutions and Economic Performance. Harvard University Press.

Besley, T. and McLaren, J. (1993). Taxes and bribery: The role of wage incentives. Economic Journal, 117(4):1415-1451.

Che, J., Chung, K.-S., and Qiao, X. (2013). The good, the bad, and the civil society. Journal of Public Economics, 106:68 - 76.

Che, J., Chung, K.-S., and Qiao, X. (2014). Career concerns, beijing style. working paper.

Che, J., Chung, K.-S., and Qiao, X. (2017). "The king can do no wrong": on criminal immunity of leaders. Nottingham Interdisciplinary Centre for Economic and Political Research NICEP Working Paper 2017-04.

$\mathrm{Du}, \mathrm{J}$. and $\mathrm{Xu}, \mathrm{C} .(2007)$. Regional competition and regulatory decentralization: the case of China. World Economy and Finance Research Programme.

Ehrenberg, R. and Bognanno, M. (1990). Do tournaments have incentive effects? Journal of Political Economy, pages 1307-1324.

Eriksson, T. (1999). Executive compensation and tournament theory: Empirical tests on danish data. Journal of Labor Economics, 17:262-280.

Guo, Y. (2013). Six tendencies of corruption and anti-corruption in contemporary China. Chinese Public Administration, 331:60-63.

Jia, R., Kudamatsu, M., and Seim, D. (2015). Political selection in China: the complementary roles of connections and performance. Journal of the European Economic Association. forthcoming.

Laffont, J.-J. and N'Guessan, T. (1999). Competition and corruption in an agency relationship. Journal of Development Economics, 60:271-295.

Landry, P. F. (2008). Decentralized Authoritarianism in China: The Communist Party's Control of Local Elites in the Post-Mao Era. Cambridge University Press.

Lazear, E. P. and Rosen, S. (1981). Rank-order tournaments as optimum labor contracts. Journal of Political Economy, 89(51).

Li, H. and Zhou, L.-A. (2005). Political turnover and economic performance: the incentive role of personnel control in China. Journal of Public Economics, 89(9-10):1743 - 1762. 
Li, X., Liu, C., Weng, X., and Zhou, L.-A. (2018). Target setting in tournaments: Theory and evidence from china. Economic Journal. forthcoming.

Maskin, E., Qian, Y., and Xu, C. (2000). Incentives, information, and organizational form. The Review of Economics Studies, 67(2):359-378.

Qian, Y. and Xu, C. (1993). Why china's economic reform differ: The m-form hierarchy and entry/expansion of the non-state sector. Economics of Transition, 1:135-170.

Rosen, S. (1986). Prizes and incentives in elimination tournaments. The American Economic Review, 76(4):701-715.

Svensson, J. (2005). Eight questions about corruption. Journal of Economic Perspectives, $19(3): 19-42$.

Tirole, J. (1992). Collusion and the theory of organizations. In Laffont, J.-J., editor, Advances in Economic Theory: Sixth World Confress, chapter 3. Cambridge University Press.

Tirole, J. (1994). The internal organization of government. Oxford Economic Papers, 46(1):129.

$\mathrm{Xu}, \mathrm{C}$. (2011). The fundamental institutions of China's reforms and development. Journal of Economic Literature, 49(4):1076-1151. 


\section{Table 1: Parameter Values in the Model Simulation}

\begin{tabular}{lll}
\hline Model notation & Interpretation & Parameter value \\
\hline (a) Exogenous & $r_{i}, i=1,2,3$ & \\
& & \\
$n_{1}, n_{2}, n_{3}$ & Number of competitors per position at each level & $25,10,10$ \\
$\alpha, \beta, \gamma$ & Shape parameters in the county production function & $0.2,0.3,0.3$ \\
$\mathcal{A}$ & TFP parameter in the county production function & 7.236 \\
$\sigma_{1}^{2}, \sigma_{2}^{2}, \sigma_{3}^{2}$ & Variance of luck in competition at each level & $0.0003011 / \alpha^{2}, 0.0005289 / \beta^{2}$, \\
$\kappa$ & Cost of effort parameter & $0.0017244 / \gamma^{2}$ \\
$K$ & Wealth of a county official & 80 \\
$K$ & Rate of return on private wealth at each level & 8 \\
$r_{1}, r_{2}, r_{3}$ & Discount of collusion income to the inspector & $1.6,1.4,1.2$ \\
$\delta$ & & 0.0004 \\
& & \\
(b) Endogenous & $r_{i}\left(x_{i}\right) \equiv \bar{r}_{i}-\frac{1-e^{-\lambda x_{i}}}{1+e^{-\lambda x_{i}}}\left(\bar{r}_{i}-\underline{r}_{i}\right), i=1,2,3$ & \\
& & \\
$\lambda$ & Sensitivity parameter in the rate of return functions & 0 to 4 at 0.2 increment \\
$\bar{r}_{1}, \bar{r}_{2}, \bar{r}_{3}$ & Upper bound on the rate of return at each level & $1.6,1.4,1.2$ \\
$\underline{r}_{1}, \underline{r}_{2}, \underline{r}_{3}$ & Lower bound on the rate of return at each level & $1.05,1.05,1.05$ \\
\hline
\end{tabular}

Notes: This table contains the parameter values of the model in the simulation exercise detailed in Section 3. Panel (a) contains the parameterization of the baseline model with exogenous rates of return from rentseeking on private wealth (Section 3.2). Panel (b) contains the additional parameters in the function of the rates of return from rent-seeking, when we endogenize those rates (Section 3.3). 
Figure 1: The Geographic, Organizational and Demographic Structure: An Illustration with $n_{1}=3$ and $n_{2}=2$

(a) The Geographic and Organizational Structure

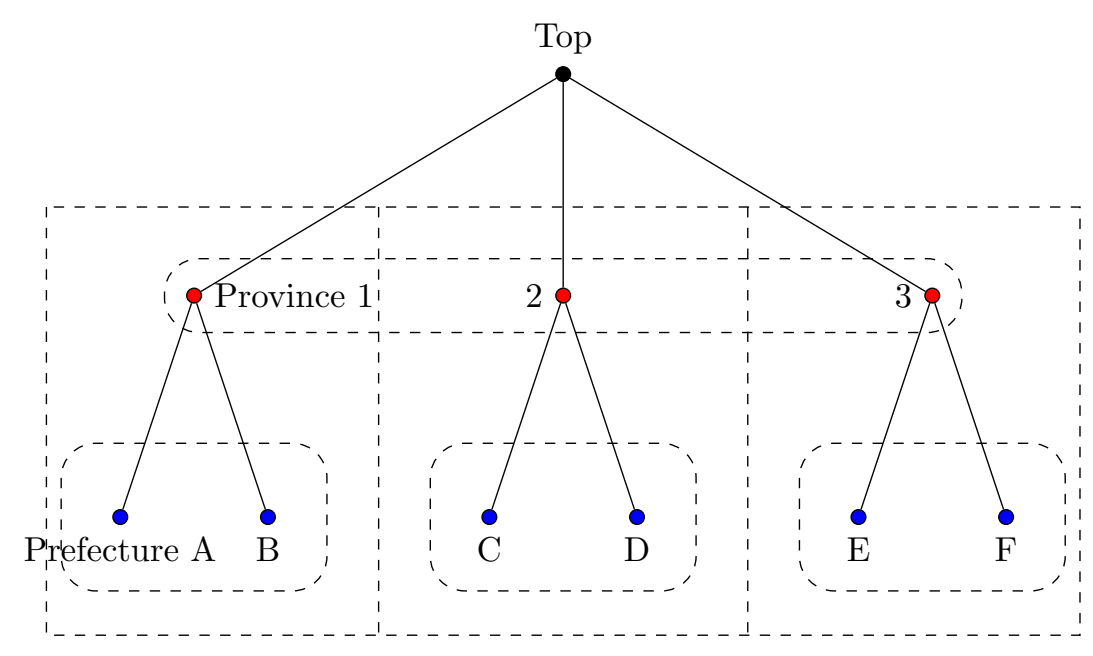

(b) The Demographic Structure

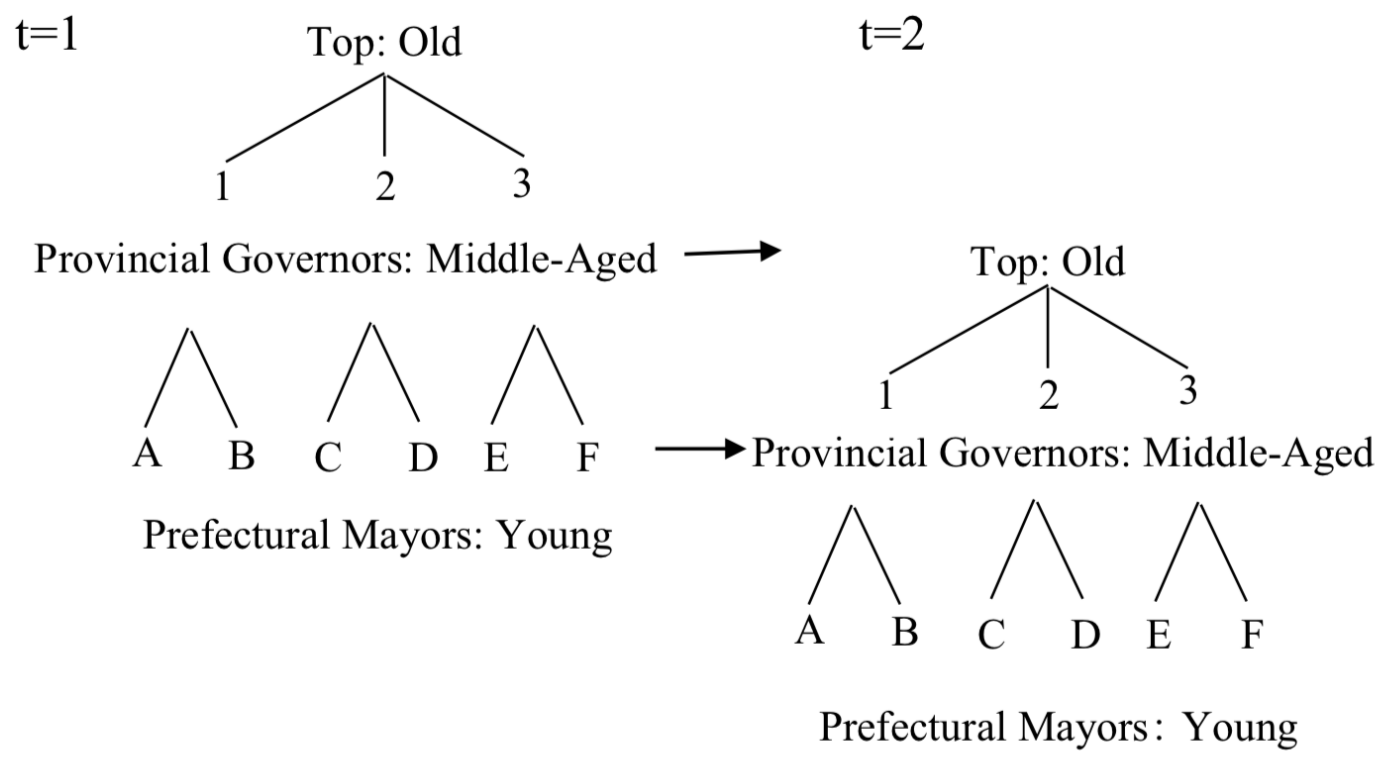

Notes: This figure illustrates the geographic, the organizational and the demographic structure of the model when there are three provinces and two prefectures per province. In Panel (a), the enclosures denote the geographic structure on which production is based. The branches in Panel (a) illustrate the organizational structure of the bureaucracy that manages the production tasks. In Panel (b), the demographic structure is illustrated with two overlapping generations, where prefectural mayors are drawn from the young generation every period; provincial governors are promoted from last period's young prefectural mayors who become middle-aged; the top leader is promoted from last period's middle-aged provincial governors who become old. All losing officials in the promotion tournament are absorbed in non-leadership posts at the exiting rank. For a detailed description of the model setup, see Section 2. 
Figure 2: Baseline Model: Varying the Wealth Endowment, $K$

(a) Wage Scale $W_{i}$, Varying $K$

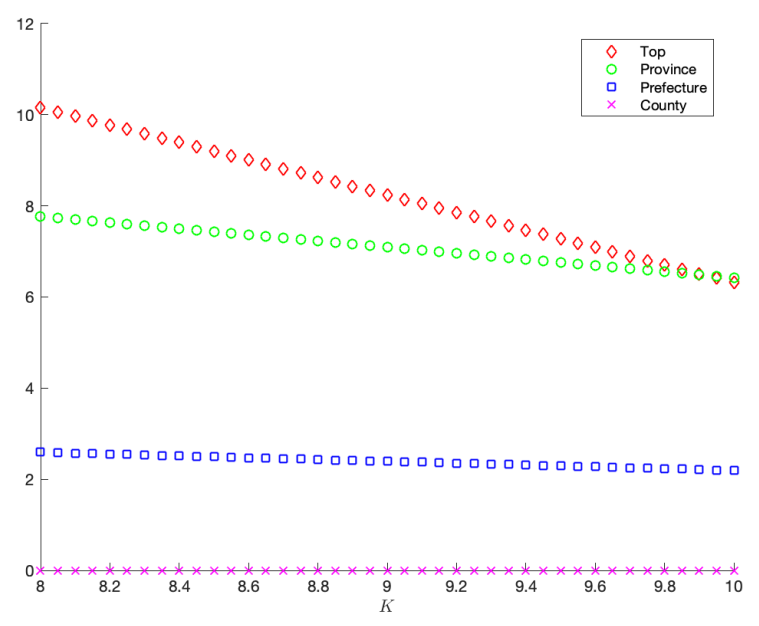

(b) Effort Level $x_{i}$, Varying $K$

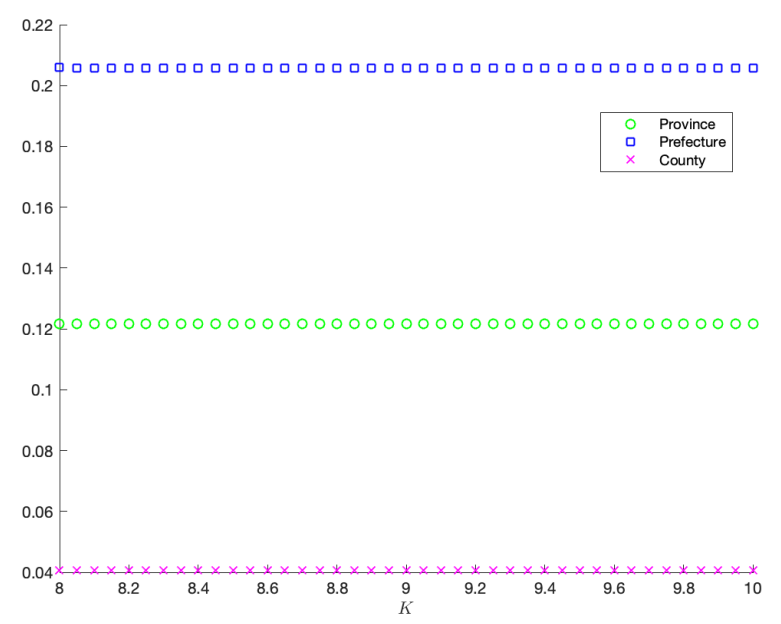

(c) County Growth Rate $y$, Varying $K$

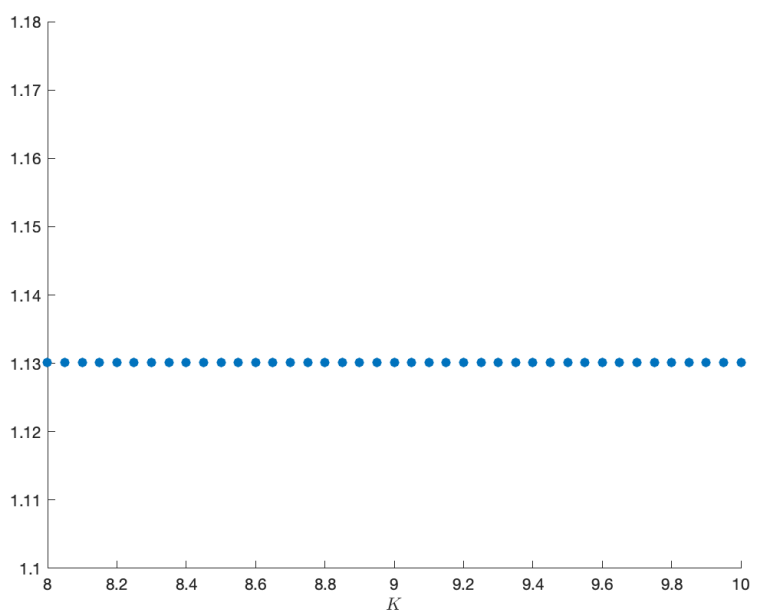

Notes: This figure shows the results from the simulation of the baseline model with four levels of government and exogenous rates of return from rent-seeking, when 32 we vary the county heads' private wealth endowment, $K$. For a discussion of the results, see Section 2.4.2. 
Figure 3: Model with Endogenous Returns: Varying the Sensitivity of Returns to Effort, $\lambda$

(a) Wage Scale $W_{i}$, Varying $\lambda$

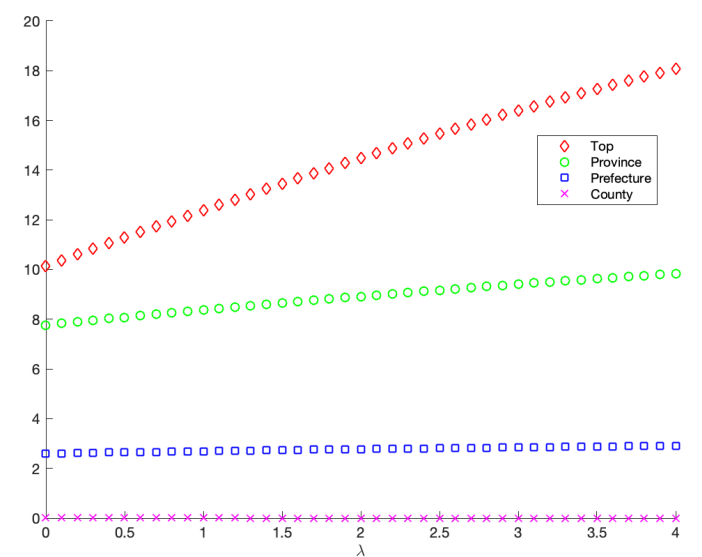

(c) Endogenous Returns $r_{i}$, Varying $\lambda$

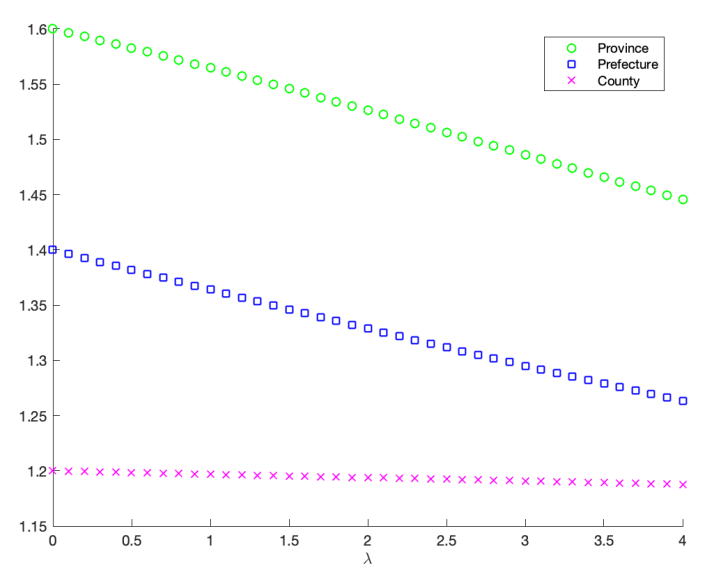

(b) Effort Level $x_{i}$, Varying $\lambda$

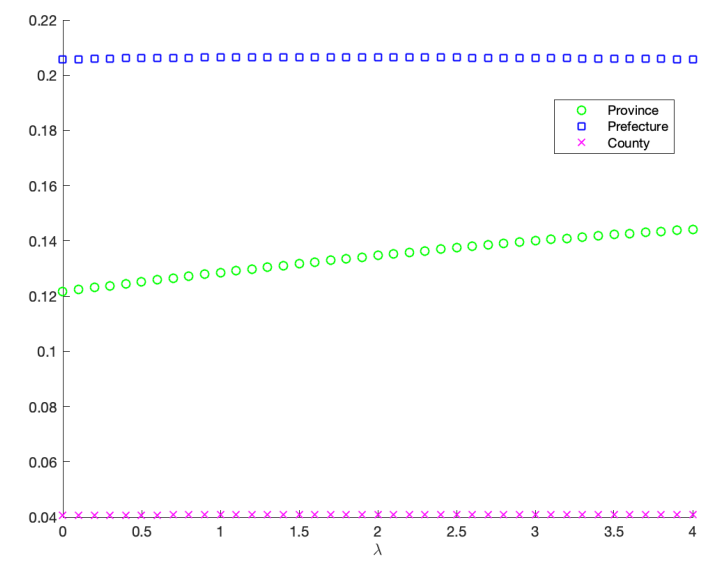

(d) County Growth Rate $y$, Varying $\lambda$

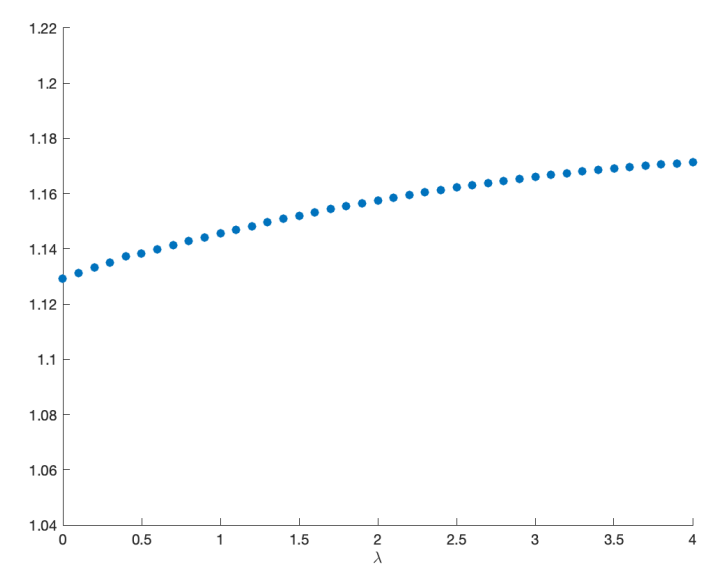

Notes: This figure shows the results from the simulation of the extended model with four levels of government and endogenous rates of return from rent-seeking, when we vary the sensitivity of returns to effort, $\lambda$. For a discussion of the results, see Section 3.3. 